\title{
Destellos de la VIDA DEL INVENTOR DEL MICROSCOPIO, ROBERT HOOKE
}

Flashes from the life of the inventor of the microscope, Robert Hooke

\section{Uriel García-Cáceres ${ }^{1}$}

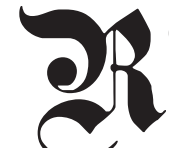

esulta interesante comentar algunos aspectos de la vida de un destacado científico inglés cuya trayectoria vital fue olvidada y despreciada por mezquindades, producto de envidias de otro de sus colegas e igualmente científico; pero, celoso de la fama de sus pares. Se trata de glosar algunos aspectos de la singular vida de Robert Hooke (1635-1703).

Nacido en la isla inglesa Wight, situada en el Canal de la Mancha. Hijo de una destacada familia de sacerdotes anglicanos que le proporcionaron una excelente educación superior. Dicen que, Robert Hooke, era irascible y engreído, con su cuerpo deforme por una giba congénita en su columna vertebral. Pero, fue un brillante ejecutor de una gran variedad, de descubrimientos y obras. Desde demostrar la elasticidad de los metales (espirales, resortes o muelles) con la consiguiente formulación de las reglas físicomatemáticas, las que hoy se conocen con el

Profesor emérito. Facultad de Medicina, Universidad Peruana Cayetano Heredia. Titular de la Cátedra Pedro Weiss, UPCH. Académico Honorario, Academia Nacional de Medicina, Lima, Perú.

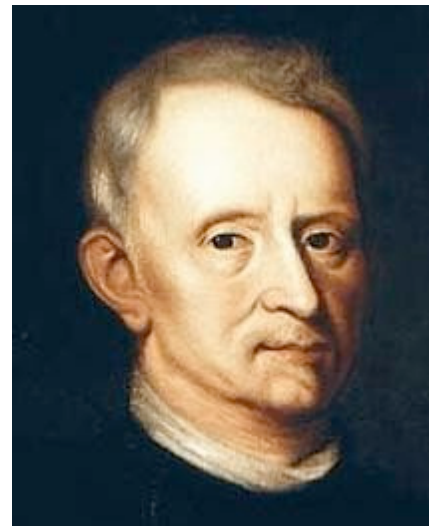

Supuesto retrato de Robert Hooke, realizado por Mary Beale según Lisa Jardine.

apelativo "Ley Hooke". (1) Demostró dicha elasticidad rítmica construyendo, por ejemplo, el espiral metálico de los relojes sin péndulo (Figura 1). Robert Hooke fue el inventor del resorte elástico metálico del segundero de relojes que reemplazó al reloj de péndulo. Así facilitó a la navegación por calcular los meridianos con exactitud. Diseñó y construyó el primer microscopio compuesto, jamás antes ideado (Figura 2); o, también, la construcción de las escaleras "caracol" para las edificaciones cilíndricas, en lugar de las peligrosas escaleras rectilíneas.

1 La ley de Hooke es el principio físico en torno a la conducta elástica de los sólidos. Fuete: https:// concepto.de/ ley-de-hooke/\#ixzz6KSpvfwpw 


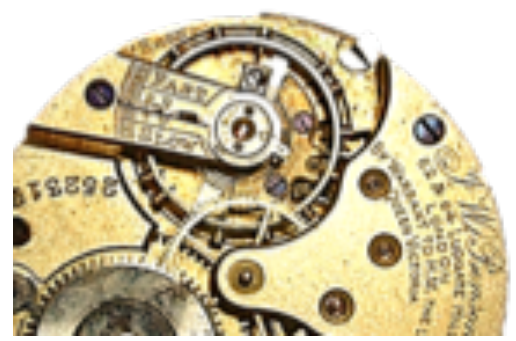

Figura 1. Fuente: Fotografía de antiguo reloj, tomada por el autor de este trabajo.

Las fuentes principales para pergeñar estas líneas son dos: la biografía escrita por la destacada historiadora inglesa Lisa Jardine (1944-2015), titulada: The Curious Life of Robert Hooke (2); y, una versión original digitalizada en CD-Octavo de la obra de Robert Hooke titulada: Micrographia. ${ }^{(3)}$ publicada en 1665. Esas dos obras las poseemos en nuestra biblioteca.

Su enemistad con Sir Isaac Newton ${ }^{(4)}$, el famoso sabio que formuló las leyes de gravitación, quien gozó de un enorme prestigio y poder social, hizo que Hooke fuese relegado $\mathrm{y}$ olvidado, principalmente en The Royal Society de Londres. Según datos recogidos de las actas de esa prestigiosa entidad, el odio que Newton profesó contra Hooke era tal que mandó destruir los dos únicos retratos de su malquerido personaje. Ese conflicto se generó por reclamo, durante las sesiones de la sociedad científica de Londres, The Royal Society, por no ser mencionado o reconocido

2 Jardine, Lisa: "The Curious Life of Robert Hooke" 2004, Harper Collings Publisher, Great Britain. La historiadora Lisa Jar dine (1944-2015) fue una académica profesora de historia del Renacimiento, del Center for Editing Lives and Letters en la Queen Mary University of London.

3 Hooke, Robert: "Micrographia", or More Physiological Descriptions of Minute Bodies Made by Magnified Classes. With Observations and Inquiries Thereupon. London, Printed by J. Martyn and J. Allestry. 1665.

4 Newton le reclamó a Hooke, en una conversación: Solo porque uno dice que una cosa puede ser, es la prueba de haber comprobado esa aseveración, cuando Hooke postuló, antes que Newton demostrara matemáticamentequelaintensidad degravedad esel cuadrado delainversa dela masa. (Enellibro de Lisa Jardine, (Op. Cit.). Este fue el inicio de una porfiada enemistad entre ambos.

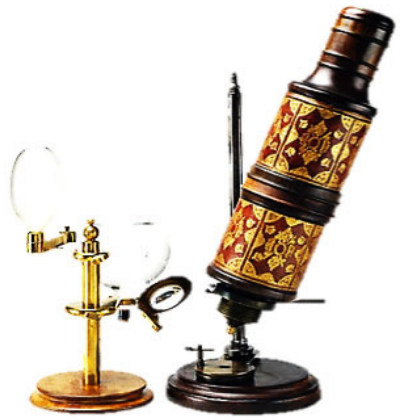

Figura 2. Fotografía del microscopio inventado y construido por Robert Hooke, en 1664. Museo de The Royal Society of London.

(Newton a Hooke) por haberle formulado, teóricamente, el sustrato matemático de las leyes de la gravedad. Dicho sea de paso, este modelo de situaciones siempre ha ocurrido y ocurre, aquí y en todos los escenarios de la vida humana en sociedad.

Para demostrar la variedad de actividades y la fama de sabio multifacético que tuvo Hooke, hay que recordar que él actuó como el arquitecto reconstructor de la ciudad de Londres luego del pavoroso incendio de esa metrópoli, ocurrido del 2 al 5 de setiembre de 1666, que destruyó gran parte del centro

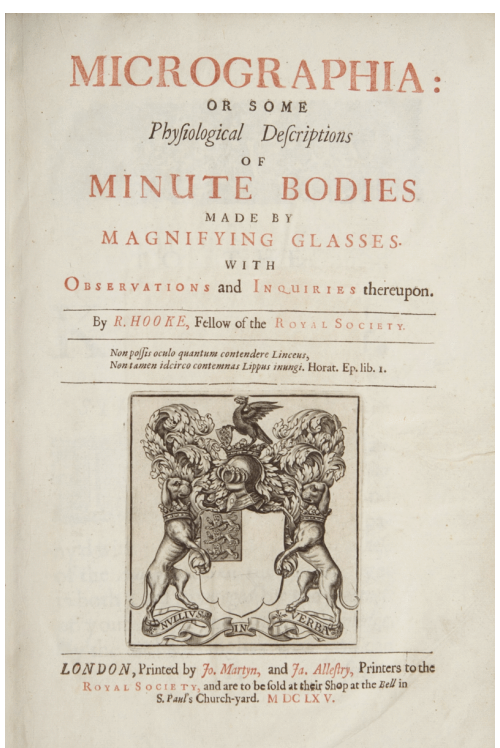

Figura 3. Carátula de Micrographia, editado por The Royal Society, en 1665. 

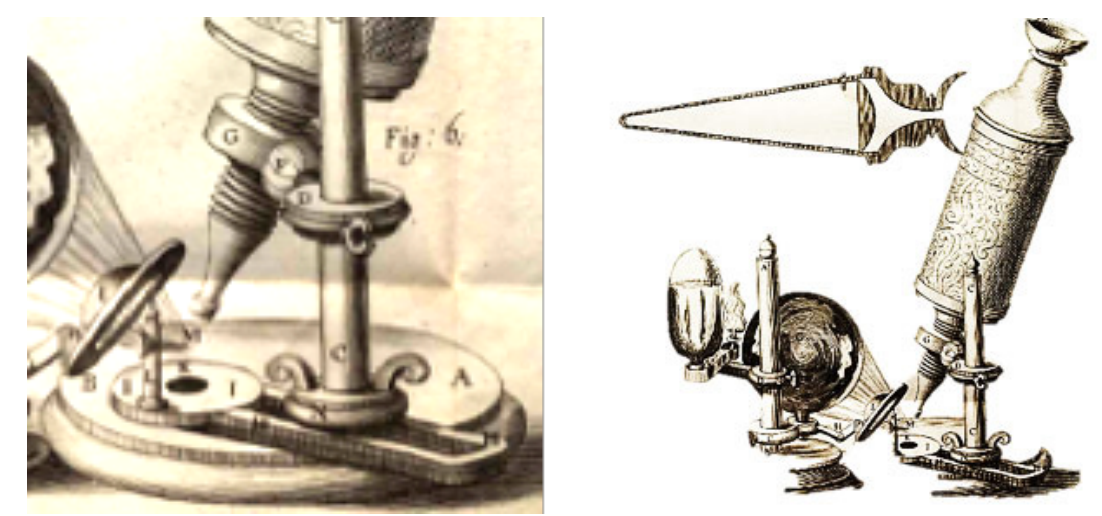

Figuras 4a y 4b. Composición física del microscopio que Robert Hooke inventó en 1664. Imágenes tomadas de Micrographia.

histórico de dicha ciudad. Entre los numerosos edificios que reedificó estuvo el del Royal College of Physicians; $\mathrm{y}$, construyó una torre cilíndrica conmemorativa de dicha catástrofe en la que instaló, precisamente, la primera escalera caracol del mundo. Dicha torre, termina en un espectacular mirador en el vértice, con balaustrada externa circular. Hoy día, es una atracción turística.

Luego interesa exponer la motivación que tuvo Hooke por la microscopía, Él debe ser considerado como el primer "microscopista" del mundo en la historia de la ciencia.

En el prefacio de su libro Micrographia, razonó así: "Por medio de los telescopios nada esta tan distante a nuestra vista; pero, con la ayuda de los microscopios, nada hay tan pequeño que pueda escapar a nuestros ojos; luego, hay todo un nuevo mundo para ser descubierto" (5) (Traducción libre). Esta premonición tiene una fascinante actualidad, al pensar que fue expresada en 1665. Desde que, hasta ahora, no se agota la posibilidad de hallar, con el uso del microscopio, algo nuevo en el medio ambiente en el que los humanos vivimos.

5 Hooke, Robert. (Op. Cit) By the means of the telescopes there is nothing so far distant but. may be represented to our view; and by the help of Microscopes, there nothing so small, as to escape our inquiry; hence there is a new visible world to be understanding... (tercera página sin numerar del Prefacio).
Por ello construyó el primer microscopio compuesto de la historia. Como se observa en las figuras, con ocular instalado en la parte superior de un tubo (barril) en cuyo extremo distal puso un lente objetivo. Este aparato estuvo sostenido por un pedestal en el que instaló un sistema de enfoque. Además, una fuente de luz, que consiste en una lampara de mechero que condensa su destello por medio de una esfera de vidrio llena de agua cristalina y un lente condensador (Figuras $4^{a}$

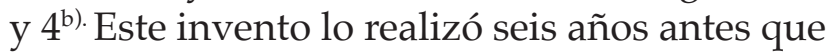
la lupa de Leeuwenhoek fuera construida, erróneamente considerada historia como el primer microscopio.

Posiblemente, para la historia de la biología, general y humana, una de las más importantes contribuciones que Hooke realizó con su microscopio fue el haber descubierto que los organismos vivientes, plantas y animales están constituidos por lo que él llamó" "celdas", para después proponer el sustantivo "célula" (Figura 5).

Hooke estimuló a varios investigadores que leyeron sus escritos. Por ejemplo, cuando Antoni van Leeuwenhoek, aquel mercader de telas finas en Delft, Holanda, quien estuvo en Londres, en 1668, observó la figura 3 del libro Micrographia, de la obra de Hooke, que ahora 


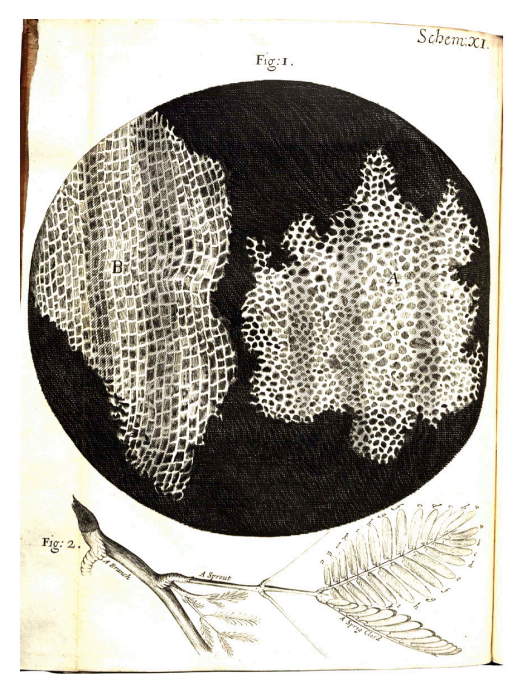

Figura 5. Dibujo de la estructura celular del corcho. Págs. 114-115 de Micrographia.

desplegamos, mostrandola trama "histológica" de las telas: sedas y tafetanes (Figura 6). Estas imágenes estimularon al holandés a usar lentes de aumento para observar sus propias telas; y, después, ser un destacado descubridor y observador de microbios. ${ }^{(6)}$

Claro está que ese mercader de telas holandés, Antoni van Leeuwenhoek (1632-1723), sin ningún diploma académico, pero con una porfiada y genial curiosidad, construyó un aparato óptico (Figura 7) con el que descubrió la existencia microbios vivientes invisibles a simple vista, entre la costra sarrosa de sus dientes o en cualquier gota de agua, así como los elementos celulares que flotan en la sangre humana $\mathrm{y}$, como si todo ello fuera poco, los espermatozoides en su propio semen. ${ }^{(7)}$

Sin embargo, repetimos, el común de los biólogos y médicos, cuando revisan la

6 In 1668, van Leeuwenhoek paid his first and only visit to London, where he probably saw a copy of Robert Hooke's 'Micrographia' (1665) which included pictures of textiles that would have been of interest to him. https: / /www.bbc.com/mundo/ noticias- 47422115

7 De Kruif, Paul: “Antonio van Leeuwenhoek, el Primer Cazador de Microbios", en Los Cazadores de Microbios. Buenos Aires: Editorial Claridad, 1949; pp.: 11-36

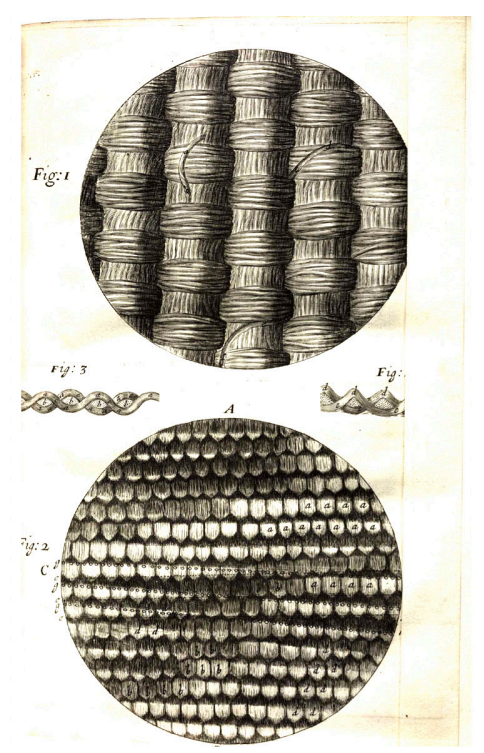

Figura 6. Dibujos de las tramas de tela de seda (arriba) y de tafetán (abajo). Págs. 4-5 de Micrographia.

historia, consideran que la pequeña lupa que Leeuwenhoek inventó, en 1670, seis años después del microscopio de Robert Hooke como el primer de estos aparatos creado en la historia, en 1664. El aparato óptico del holandés consta de un pequeño lente de 200X de aumento, montado entre dos láminas de bronce, en el que se ha instalado un dispositivo de enfoque (Figura 7).
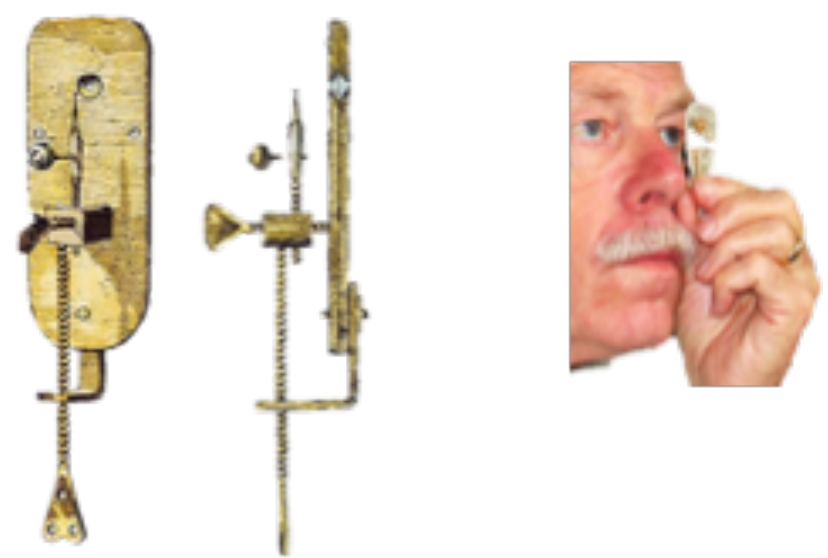

Figura 7. Microscopio simple de Antoni van Leewenhoek, 1670. 


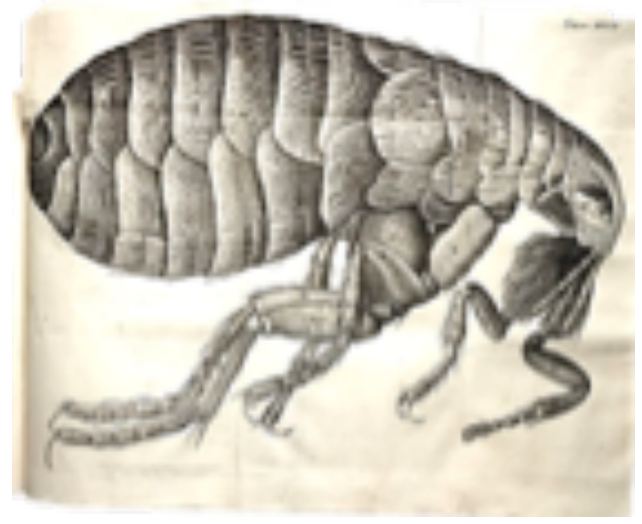

Figura 8. La pulga. Micrographia: Figura en hoja desplegable, entre pp. 210-211.
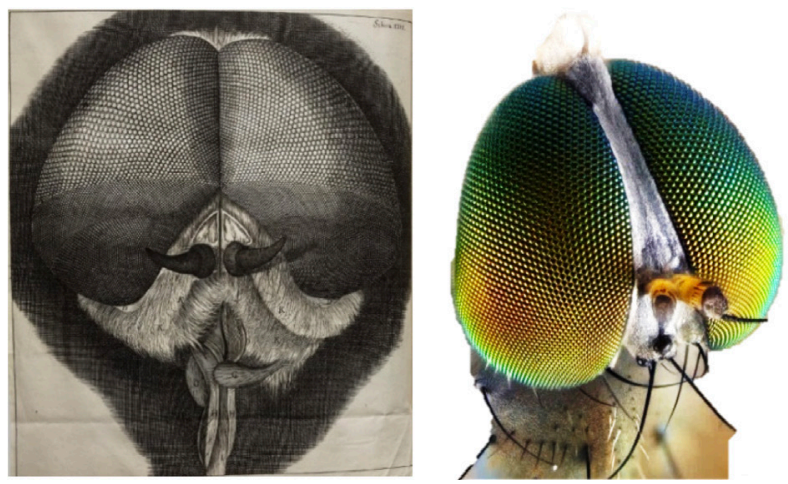

Figura 9. Izq. Ojos y cabeza de una mosca, Micrographia, lámina entre pp. 174-175. Der. Ojos y cabeza de una mosca con la técnica de barrido por microscopía electrónica.

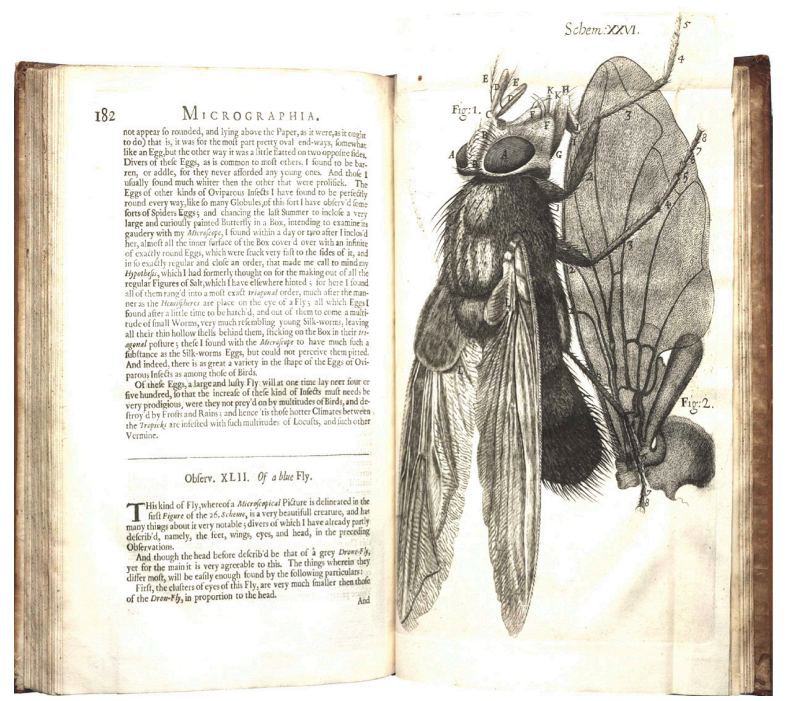

Figura 10. La mosca casera. Micrographia, lámina a página desplegable, entre pp. 182-183.
Robert Hooke, como secretario de The Royal Society, en Londres, fue el encargado de recibir las cartas que Leeuwenhoek envió, durante varias décadas, describiendo sus hallazgos. Su relación epistolar con el holandés mercader de telas y microscopista fue buena, a pesar del estado de tensión chauvinista de ambos por el estado de postguerra entre Inglaterra y Holanda.

Nadie, hasta la publicación del libro Micrografía, de Hooke, conocía la real apariencia de una pulga, la de un piojo o de una mosca con gran detalle, tal como se aprecia en las imágenes que reproducimos luego.

Cuando, hoy día, un observador curioso acude a Google para indagar la imagen de insectos, allí están las producidas por Hooke junto a las modernas fotografías obtenidas con el uso de microscopios estereoscópicos. Lo que confirma la exactitud de sus imágenes obtenidas en el siglo XVII.

La pulga fue objeto de la atención de Robert Hooke (Figura 8). Dijo que se trataba de una criatura con una extraordinaria energía, la que atribuyó a la estructura de sus patas. El detalle de su morfología externa está corroborado por modernas fotografías obtenidas con el uso de microscopios estereoscópicos.

Sus dibujos de la mosca casera son notables (Figuras 9 y 10). Del piojo, Hooke comentó que era una "criatura que en cualquier momento de la vida de un ser humanos ha de cohabitar con él" (Figura 11, prendido con sus ganchos de un pelo, con su cavidad gástrica prominente). Claro que, en nuestros tiempos, su presencia va acompañada de la pobreza, como patrimonio de la injusticia social.

De la hormiga dijo: "esta criatura nunca esta quieta, tuve que fijarla con parafina o goma para poder dibujarla, Su cuerpo es tan pequeño que se 


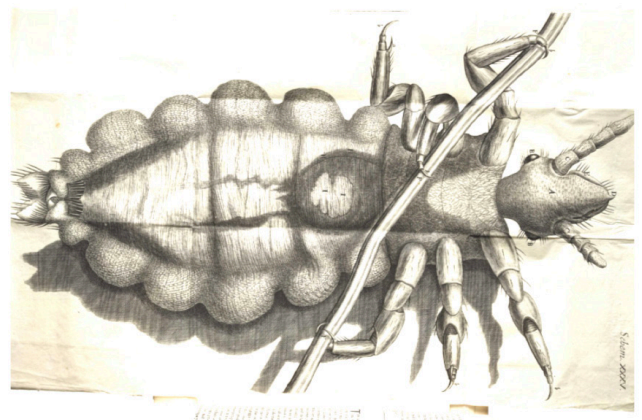

Figura 11. El piojo. Dibujo de gran dimensión en una hoja de tres dobleces, Micrographia, entre la pp. 211-212.

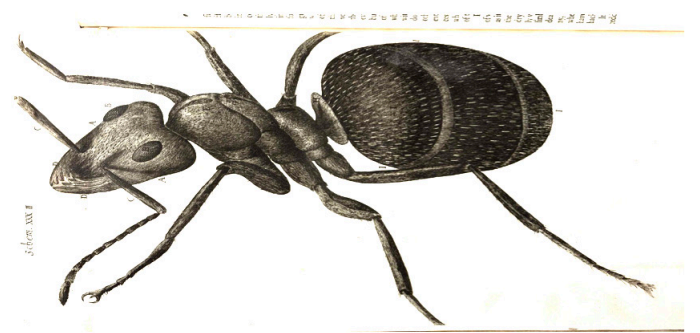

Figura 12. Hormiga. Micrographia, lámina entre las pp. 202-203.
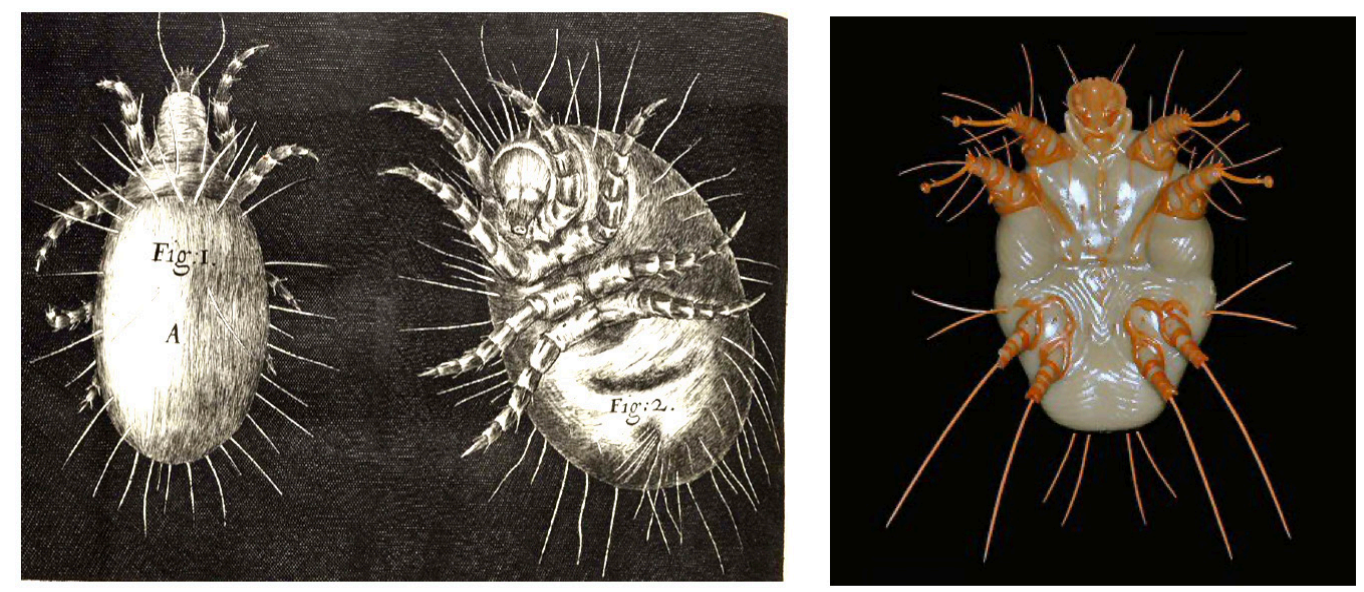

Figura 13. Ácaro. A. Micrographia, lámina entre las pp. 213-214. B. Ácaro bajo microscopio estereoscópico moderno.

me hizo muy difícil representarlo adecuadamente" (Figura 12). Logró tranquilizarla rociándole una gota de licor (spirit of wine).

Entre las páginas 214 y 215, de Micrographia, está la descripción del ácaro. Dice que su tamaño es tan pequeño que se necesita lunas de aumento para distinguirla, que siendo blancas se necesita observarlas en una superficie negra, tal como hasta ahora se requiere (Figuras 13a y 13b).
Cumplimos, en esa ocasión con dar a conocer un destello de la vida de un científico, multifacético, cuyas contribuciones fueron un destello que hasta ahora ilumina la historia de la ciencia.

\section{CORRESPONENCIA:}

Uriel García-Cáceres, ugarca@yahoo.es

Fecha de recepción: 10 de mayo del 2020. Fecha de aceptación: 24 de mayo del 2020. 